Models for predicting the seepage velocity and seepage force in a fiber reinforced silty soil

\author{
A. R. Estabragh \\ Tel: +982612241119 \\ Fax: +98261 2226181 \\ Email: raeesi@ut.ac.ir
}

Associate Professor, Faculty of Soil and Water Engineering, University of Tehran, PO BOX 4411 Karaj 31587-77871, Iran

\begin{abstract}
A. Soltani
Postgraduate Student, Faculty of Soil and Water Engineering, University of Tehran, PO BOX 4411 Karaj 31587-77871, Iran
\end{abstract}

Tel: +98 2612241119

Fax: +98261 2226181

Email: A.Soltani@ut.ac.ir
A. A. Javadi
Professor, Computational Geomechanics Group, School of Engineering, Computer Science and Mathematics, University of Exeter, Devon, EX4 4QF, UK
Tel: +44 1392263640
Fax: +44 1392217965 


\title{
Models for predicting the seepage velocity and seepage force in a fiber reinforced silty soil
}

\begin{abstract}
Randomly reinforced soil is used in hydraulic projects such as temporary canals, earth dams, stream restoration and so on for controlling seepage. This paper presents an investigation into the effect of random reinforcement on the seepage velocity and seepage force in a silty soil. Experimental tests were carried out on randomly reinforced samples with two types of fiber at different lengths and percentages. The results show that the random reinforcement of soils with fiber is an effective technique in controlling the seepage velocity and seepage force. Regression models were developed based on the experimental data for determination the seepage velocity and seepage force. The proposed models include the length of fiber, fiber content of soil and hydraulic gradient. Comparison between the model predictions and the experimental results shows that the proposed models can satisfactorily predict the seepage velocity and seepage force for a randomly reinforced silty soil. Analysis of the results of the proposed models shows that the seepage velocity increases with increasing the hydraulic gradient but decreases with increasing fiber length and fiber content. In addition the seepage force increases with increasing the fiber length and fiber content of the soil.
\end{abstract}

Key words: seepage velocity, seepage force, hydraulic gradient, randomly reinforced, silty soil, regression 


\section{Introduction}

Water can flow in a soil mass under a hydraulic gradient. When water flows through a soil its energy is transferred to the soil skeleton and this leads to a seepage force applied to the soil skeleton. When the flow of water is in the upward direction the seepage force tends to lift the soil mass by reducing its effective weight. If the seepage force exceeds the weight of the soil the resultant force will be acting upward and soil would become unstable. In this condition the erosion would progress backward along the flow line until an erosion path, nearly in pipe shape is formed. This kind of soil erosion is termed piping. During piping the hydraulic gradient reaches to a value that is termed critical hydraulic gradient $\left(i_{c}\right)$. Piping is a common problem in earth embankments ([1]). Brown and Graham ([2]) reported the failure of a number dams in the USA and concluded that the failure of them was due the occurrence of piping. It has been reported that failure of embankment dams due to piping is about $0.5 \%$ and about $1.5 \%$ of them experience the piping phenomenon ([3]). Foster et al. ([3]) and Ojha et al. ([4]) state that piping usually occurs in earth structures that are made up of loose soil with high permeability. Failure of hydraulic structures such as irrigation canals, temporary check dams and soil structures has been attributed to seepage-induced piping ([5]). Ubilla et al. ([6]) investigated the failure of the levees and flood wall protecting New Orleans, Louisana, USA and surrounding areas during Hurricane Katrina. They concluded that one of the main reasons for the failure was piping. It is therefore necessary to reduce the energy of flow of water and control the seepage force in order to increase the safety of hydraulic structures against piping. There are many methods to prevent from piping failure and to increase the 
piping resistance of the soil such as using cut off walls, trenches, sheet piling, blankets of impervious material and pressure relief wells.

Randomly reinforcement soil is one of the mechanical methods that has been used to improve the mechanical properties of soil. In this method soil is mixed with randomly distributed discrete fibers. One of the main advantages of using randomly distributed fibers is that they are deposited in a mass independent of each other and have an equal probability of occurrence in any portion of the composite mass ([7]). They have an equal probability of making all possible angles with an arbitrarily chosen axis ([8]). The majority of previous research work has been done on the strength of granular soils randomly reinforced with fibers $([9]-[12])$. The results of these research works have shown that reinforcing soil with randomly distributed fibers increases the strength of the soil. Furumoto et al. ([13]) introduced, for the first time, the randomly reinforced soil in the downstream of hydraulic structures to resist against piping. Furumoto et al. ([13]) conducted laboratory and field tests on randomly reinforced soil (for application in river levee) and concluded that the use of randomly reinforced soil is an effective method for stabilization of soil against piping. Sivakumar Babu and Vasudevan ([5]), Das et al. ([14]) and Das and Viswanadham ([15]) performed experimental tests on reinforced soil samples in a special apparatus that simulates the upward flow of water. They found that soil reinforcement is a suitable method to control piping. The previous investigations on the use of reinforced soil to improve the resistance of soil against piping are limited to very small diameter fibers (in the range of $\mu \mathrm{m})$ that could be impractical in field applications. Estabragh et al. ([16]) conducted experimental tests on two types of fiber (polyester and polyethylene) with large diameters $(0.2$ and $0.28 \mathrm{~mm})$ and different percentages for improving piping 
resistance and controlling the seepage velocity of a sandy silty soil. The main aim of this work is carry out statistical analysis of the experimental results that were presented by Estabragh et al. ([16]) and develop a suitable regression model to describe the piping behavior. In development the regression relationships fiber length, fiber content of soil and hydraulic gradient were considered as the key parameters that have significant effect on piping.

\section{Experimental tests}

\section{1- Apparatus}

Skempton and Brogan ([17]) designed and fabricated an apparatus for studying the piping phenomenon in sandy gravel material. After that researchers such as Furumoto et al. ([13]), Sivakumar Babu and Vasudevan ([5]), Das et al. ([14]) and Das and Viswanadham ([15]) used an apparatus, almost similar to the Skempton and Brogan's apparatus. By studying the apparatuses that were used by the above researchers a simple apparatus was designed and fabricated for conducting one dimensional piping tests as shown in Fig.1. The main function of this apparatus is to simulate the upward seepage through the soil sample as discussed by Estabragh et al. ([16]). In the apparatus the sample can be subjected to an upward flow of water under different hydraulic heads. The hydraulic gradient $(i)$ can be determined at each stage of the test by the following relationship:

$i=\Delta h / L$

where $\Delta \mathrm{h}$ is the differential head between in the beginning and at the end of the sample, $\mathrm{L}$ is the length of the sample.

\section{2- Material}

2-1-soil 
A silty sand soil consisting of $77 \%$ sand and $23 \%$ silt was used in this work. The physical and mechanical properties of the soil are shown in Table.1. This soil can be classified as SM (sand with silt) according to the Unified Soil Classification System.

\section{2-2-Fiber}

Polyethylene and polyester fibers in filament form with diameters of 0.28 and 0.20 mm were used in this work. The strength characteristics (tensile strength and elastic modulus, measured in the laboratory) and the other properties of fibers (obtained from the manufacture) are summarised in Table. 2

\section{3- Sample preparation}

Fibers with lengths of 5,25, 35 and $50 \mathrm{~mm}$ and percentages of $0.5,0.75,1$ and $1.5 \%$ (weight of air dry soil) were used in this work. The mixing of fiber and the soil was done according to the methods that was used by researchers such as [18] and [9]. Compaction tests were performed on the natural soil and the reinforced soil according to the ASTM standard. In the preparation of the samples for natural or reinforced soil they were mixed with an amount of water corresponding to optimum water and mixing was done by hand. Preparation of the samples was done by static method in a special mould in three layers $([19])$ by a loading machine. The samples were compacted at their optimum water content to attain the maximum dry unit weight according to their compaction curve. The samples had diameter and length of 50 and $100 \mathrm{~mm}$ respectively.

\section{4- Testing program}

After preparing the samples the mould containing the sample was placed in the apparatus. The samples were saturated under $\Delta h=0.0$ for a duration of $24 \mathrm{~h}$. The piping test was conducted by increasing the head of water in the reservoir (hydraulic head) at increments of $20 \mathrm{~mm}$ while the level of water above the sample was kept 
constant at $50 \mathrm{~mm}$ (see Fig.1). The duration of each increment was about 10 minutes and during this time the discharge water from the sample was collected and its volume was measured when the rate of discharge was stabilized. The increasing of the level of water in the reservoir was continued until piping occurred in the sample. The piping was observed as the formation of small bubbles and local boiling. Seepage velocity was calculated by the Darcy's equation:

$v=k . \Delta h / L$

where $v$ and $k$ are discharge velocity and coefficient of permeability respectively. Seepage velocity $\left(v_{s}\right)$ was calculated using the following relationship:

$v_{s}=v / n$

where $n$ is the porosity of sample. For calculation of the porosity of the reinforced sample, the fibers were considered to be similar to soil solid particles. The porocity was calculated as:

$\mathrm{n}=\mathrm{V}_{\mathrm{v}} / \mathrm{V}$

where $\mathrm{V}$ is the total volume of the.

Critical hydraulic gradient $\left(i_{c}\right)$ is defined as the ratio of head of water at which the soil particles start to lift due the upward flow of water $\left(\Delta h_{c}\right)$ to the length of sample $(L)$ :

$i_{c}=\Delta h_{d} / L$

As the water flows through the soil a force is applied to the soil particles which is referred to as seepage force. The seepage force at critical gradient can be calculated by the following relationship:

$P=\gamma_{\mathrm{w}} * i_{c} * V$

where $P$ is the seepage force at critical gradient $\left(i_{c}\right), \gamma_{\mathrm{w}}$ is unit weight of water and $V$ is the volume of soil sample.

\section{Results and discussion}


Typical results of variations of seepage velocity with hydraulic gradient for the natural soil and the soil reinforced with $35 \mathrm{~mm}$ polyethylene fibers at different percentages are shown in Fig.2. Fig.3 shows similar results for a constant percentage of fiber $(0.75 \%)$ and different lengths of polyethylene fiber $(5,25,35$ and $50 \mathrm{~mm})$. Figs. 4 and 5 show the similar results as Figs. 2 and 3 for polyester fiber. It is observed from these figures that the seepage velocity-hydraulic gradient curves consist of two linear segments. The initial segment shows a nearly linear increase in seepage velocity with increase in the hydraulic gradient. The onset of the steep change in the gradient of the seepage velocity-hydraulic curves is assumed to represent the critical hydraulic gradient. After this point the seepage velocity is rapidly increased. This method of calculating the critical hydraulic gradient was used by [14] and [15]. The values of critical hydraulic gradient were determined for all piping tests (see Tables 3 and 4). The seepage force was calculated based on equation (6) and typical results for polyethylene and polyester fibres are shown in Figs. 6 and 7 respectively. The values of seepage force for the two different fibers are shown in Table 3 and 4. Figs. 2 to 4 and the data in Tables 3 and 4 show that the seepage velocity-hydraulic gradient curves are located to the right of the curves for the natural soil for both types of fiber. The results show that the polyester fiber with diameter of $0.20 \mathrm{~mm}$ is more effective in increasing the value of critical hydraulic gradient and seepage force than the fiber with diameter of $0.28 \mathrm{~mm}$. It can be said that at a constant length and percent of fiber by decreasing the diameter the number of fibers is increased in unit volume of soil. When the number of fibers is increased the friction between soil and fibers is increased which lead to increase the critical hydraulic gradient and seepage force. For a constant length and diameter of fiber the increase in the percent of fiber increases the friction between the soil particles and the fibers and-increases the critical gradient 
hydraulic. The results show that, in some cases, for a constant fiber length, the values of critical hydraulic gradient is decreased by increasing the percent of fiber. This behavior was also reported by [14]. This can be attributed to the buckling of fibers and accumulation of clusters of fibers during sample preparation and testing ([14]). Some of the results show that for samples with same length but different fiber contents the critical hydraulic gradients are the same. The results show that the critical hydraulic gradient and seepage force increase linearly up to a specific fiber content and then become constant. These results are consistent with the findings that were reported by [14] and [15]. Michalowski and Zhao ([20]) and, Michalowski and Cermak ([21]) showed that the strength of reinforced sandy soil is increased up to a limit value after which it remains constant by increasing the percent of fiber. Therefore, by substituting the constant value ( $V=$ volume of sample and $\gamma_{\mathrm{w}}=$ unit weight of water) in the equation (6) the seepage force can be considered as:

$$
P=1.96 i_{c}
$$

\section{Regression models}

Regression analysis is a general method used in many engineering and scientific problems for establishing a model or relationship between effective variables in a problem. If there is only one independent variable it is named simple linear regression but if the analysis consists of more than one variable it is called multiple regression analysis. In statistics, nonlinear regression is a form of regression analysis in which observation data are modeled by a function that is nonlinear combination of the model parameters and depends on one or more independent variables. A review of the literature shows that there has been limited work on the use of regression models in the field of randomly reinforced soils. Ranjan et al. ([22]) and Sivakumar Babu and Vasudevan ([5]) used regression analysis for predicting the effect of fiber on strength, 
seepage velocity and piping resistance. The equation that was proposed by Sivakumar Babu and Vasudevan ([5]) for calculating the seepage force was based on the percent weight of fiber for a specific length of fiber. Therefore, different lengths of fiber should have different equations. Sivakumar Babu and Vasudevan ([5]) used regression analysis to predict seepage velocity and seepage force. They concluded, based on the values of coefficient of correlation $\left(R^{2}\right)$, that the correlation between predicted and measured values of seepage velocity and seepage force is acceptable. Sivakumar Babu and Vasudevan ([5]) did not consider the length of the fiber in their model and it was valid only for a specific percent of fiber with a defined length (the length that was used in experimental work). Therefore for each length a new equation is needed. They also did not analyze and show the significance of each variable (length of fiber, percent weight of fiber and hydraulic gradient) on the seepage velocity and seepage force. The aim of this study is to investigate the effect of three independent variables including hydraulic gradient, percent weight of fiber and length of fiber on seepage velocity and seepage force for two types of fiber (polyethylene and polyester). A general form of equation is proposed for calculating seepage force that includes the percent of fiber and fiber length (deficiency the proposed model by $[5])$. The results are analyzed based on the values of coefficient of determination $\left(R^{2}\right)$ and partial derivatives of seepage velocity or seepage force due to the variables (length of fiber, percent of fiber, hydraulic gradient).The multi regression equations are in the form of MNLR (Multiple Non-Linear Regression) or MLR (Multiple Linear Regression). Comparison is made between the predicted results from proposed models and the experimental results. The general forms of the MNLR models assumed for calculating the seepage velocity and piping resistance are as:

$$
y=\beta_{0}+\beta_{1} x_{1}^{2}+\beta_{2} x_{2}^{2}+\beta_{3} x_{3}^{2}+\beta_{4} x_{1}+\beta_{5} x_{2}+\beta_{6} x_{3}+\beta_{7} x_{1} x_{2}+\beta_{8} x_{1} x_{3}+\beta_{9} x_{2} x_{3}
$$


$y=\beta_{0}+\beta_{1} x_{1}+\beta_{2} x_{2}+\beta_{3} x_{3}$

$y=\beta_{0}+\beta_{1} x_{1}^{2}+\beta_{2} x_{2}^{2}+\beta_{3} x_{1}+\beta_{4} x_{2}+\beta_{5} x_{1} x_{2}$

where $y$ is the dependent variable, $x_{1}, x_{2}$ and $x_{3}$ are the independent variables and $\beta_{0}$ to $\beta_{9}$ are the regression coefficients. Equations 9 and 10 are quadratic polynomial equations with three variables that were used for calculating the seepage velocity. Equation 3 is also a quadratic polynomial equation with two variables used for calculating the seepage force. The regression coefficient describes the partial effect an independent variable such as $x_{i}$ on the dependent variable $y$ by keeping the other in dependent variables constant. The regression coefficients can be found by defining the independent and dependent variables in matrix forms and solving a set of equations. The simultaneous equations are solved by matrix algebra as follows:

$$
A X=Y
$$

where $\mathrm{A}, \mathrm{X}$ and $\mathrm{Y}$ are matrices for unknown coefficients of $\mathrm{X}$ and $\mathrm{Y}$ values respectively. The unknown coefficients can be obtained by the following relationship: $A=X^{-1} Y$

In order to investigate the model accuracy the coefficient of determination $\left(\mathrm{R}^{2}\right)$ and Root Mean Square Error (RMSE) are used. Root Mean Square Error (RMSE) is determined for validation of the model by the following relationships:

$R M S E=\sqrt{\sum_{i=1}^{i=n} \frac{\left(x_{i e}-x_{i m}\right)^{2}}{n}}$

where $x_{i e}$ and $x_{i m}$ are the experimental and predicted data respectively and $n$ is the number of observations.

RMSE is a measure of fitness of a model and represents the differences between the predicted and observed values. RMSE has the same units as the quantity being estimated for an 
unbiased estimator. RMSE can range from 0 to unknown values. Lower values of RMSE show a better data fit to the proposed regression model.

\section{Results and Discussion}

\section{1- Seepage velocity}

The results of seepage velocity against hydraulic gradient (Figs.2-5) show that the seepage velocity is function of hydraulic gradient, fiber length and fiber content. Figs. 2-5 show that the flow of water through a randomly reinforced soil can be divided into two sections, namely section 1 before piping and section 2 after piping. In section 1 the variations of velocity with hydraulic gradient is laminar and a function of Darcy's law. Therefore, for developing a regression model section 1 of variation of velocity against hydraulic gradient was considered. In the case before piping the hydraulic gradient is less or equal to the critical hydraulic gradient. The regression equation can by considered as a second order equation with three variables.

Based on the 137 experimental data points for the polyethylene fiber and 93 data points for the polyester fiber the regression equation for seepage velocity of the two types of fiber are as follows:

For polyethylene fiber:

$$
\begin{aligned}
& V_{s}=3.4 \times 10^{-4}+1.7 \times 10^{-4} F_{c}^{2}-3.0 \times 10^{-5} i^{2}-4.8 \times 10^{-4} F_{c}+2.04 \times 10^{-3} i \\
& -2.0 \times 10^{-5} L-3.9 \times 10^{-4} F_{c} i+1.0 \times 10^{-5} F_{c} L-1.0 \times 10^{-5} i L
\end{aligned}
$$

For polyester fiber:

$$
V_{s}=3.6 \times 10^{-4}+6.8 \times 10^{-4} F_{c}^{2}-1.13 \times 10^{-3} F_{c}+1.73 \times 10^{-3} i-4.1 \times 10^{-4} F_{c} i
$$

where $V_{s}$ is seepage velocity, $F_{c}$ is percent of fiber, $L$ is length of fiber and $i$ is gradient hydraulic that is less or equal the critical hydraulic gradient. The length of fiber ( $L$ ) has not appeared in equation 15 (polyester fiber) because the coefficient of it is very small and it can be ignored. 
Figs. 8 and 9 show the calculated seepage velocity against measured values for polyethylene and polyester fibers respectively. The values of $\left(R^{2}\right)$ and Root Mean Square Error (RMSE) for the two types of fiber with the MNLR and MLR models are shown in Table 5. As shown in this table in the case of MNLR model the values of $\left(R^{2}\right)$ are 0.9595 and 0.985 for polyethylene and polyester fibers respectively. These values of $\left(R^{2}\right)$ indicate a high correlation between the calculated and measured velocities for two types of fiber. It can be said the suggested relationships for calculating seepage velocity are acceptable. It is possible that for simplicity, in relationships 14 and 15 the second order variables can be deleted and they changed from MNLR (Multiple non-linear regression) to MLR (multiple linear regression). The form of these MLR equations are as follows:

For polyethylene fiber:

$V_{s}=7.2 \times 10^{-4}-4.0 \times 10^{-4} F_{c}+1.31 \times 10^{-3} i-1.0 \times 10^{-5} L$

For polyester fiber:

$V_{s}=5.8 \times 10^{-4}-4.8 \times 10^{-4} F_{c}+1.22 \times 10^{-3} i-1.0 \times 10^{-5} L$

In the case of MLR model for seepage velocity the values of $\left(R^{2}\right)$ are 0.935 and 0.9663 for polyethylene and polyester fibers respectively.

Table 5 compares the values of $\left(R^{2}\right)$ and RMSE for the two types of fiber for the MNLR and MLR models. As shown in this table, for the MLR models the values of $\left(R^{2}\right)$ are slightly less than MNLR. These reductions are $2.55 \%$ and $1.9 \%$ for polyethylene and polyester respectively. It can be due to deleting some of coefficients but the results of the MLR method have a high correlation. The non-uniform mixing of fibers with soil is also another reason for the reduction in the values of correlation. In order to find the degree of effect the variables (hydraulic gradient, fiber content and fiber length) on the seepage velocity the partial derivatives of the multi variable 
function are used. For simplicity of the assessment, the input and output data are normalized using the following relationship:

$x_{i n}=0.8\left(\frac{x_{i}}{x_{i \max }}\right)+0.1$

where $x_{i}$ and $x_{i n}$ represent the original and normalized data respectively and $x_{i \max }$ is the maximum value of the original data. The advantage of normalizing the data is that the range of values of different parameters has no effect on the determination coefficient. The general form of standardized equations is similar to the equations 14 and 15 but with different coefficients. The form of the regression equations obtained with the normalized data are as follows:

For polyethylene fibers:

$V_{s}=0.05781+0.0939 F_{c}^{2}-0.07829 i^{2}+0.01363 L^{2}-0.39037 F_{c}$

For polyester fibers:

$V_{s}=0.10282+0.42195 F_{c}^{2}-0.01074 i^{2}+0.17124 L^{2}-0.16607 F_{c}$

$+1.70806 i+0.03672 L-0.47766 F_{c} i+0.02245 F_{c} L-0.2234 i L$

The degree of influence of each parameter on the value of seepage velocity for the above equations can be determined from the following relationship.

$$
S X_{i}=\frac{\left|D X_{i}\right|}{\sum_{i=1}^{i=n}\left|D X_{i}\right|} * 100
$$

where $S X_{i}$ is the degree of significance of independent variable $x_{i}$ in calculating the dependent variable $y$ and $n$ is the number of data points. $\left|D X_{i}\right|$ is the absolute value of partial derivative with respect to independent variable. $x_{i}$ is a general form of independent variable that can be in the form of $S_{L}$ (degree of significance of length), 
$S_{F}$ (degree of significance of fiber content) or $S_{i}$ (degree of significance of hydraulic gradient).

For example for estimating the degree of significance of length of polyethylene fibers in calculating the seepage velocity, the partial derivate of seepage velocity function with respect to the length of fiber (DL) is as:

$$
D L=\frac{\partial V_{s}}{\partial L}=0.34249 \bar{L}_{n}+0.24861 \bar{F}_{c n}-0.44886 \bar{i}_{n}-0.3043
$$

where $\bar{L}$ is average normalized length of fiber, $\overline{F_{c n}}$ is average normalized fiber content and $i_{n}$ is normalized hydraulic gradient. The partial derivatives of seepage velocity with respect to the fiber content $\left(\mathrm{DF}_{\mathrm{c}}\right)$ and hydraulic gradient (Di) have similar relationships to the above equation.

Table 6 shows the degree of significance of each parameter on the seepage value for the polyethylene and polyester fibers. As shown in this table the values of $D_{i}$ are positive for hydraulic gradient but they are negative for the fiber length and fiber content. It can be resulted that the variation of seepage velocity is reduced by increasing the fiber content and fiber length and increased by increasing the hydraulic gradient. It is also resulted from this table that for the polyethylene fiber the role of fiber length and fiber content is the same in seepage velocity but for the polyester fiber the role of fiber content is more important than fiber length. This can be explained by the fact that at a constant fiber content, the number of polyester fibers is more than polyethylene fibers because of the smaller diameter of polyester fibers and this causes non-uniform distribution of fiber in soil mass.

\section{2- Seepage force}

The experimental results showed that the seepage velocity and critical hydraulic gradient are function of fiber content and length of fiber. Therefore, the general form 
of the regression model is a multivariable of second order with two independent variables. The general form of the model was similar to equation 7. The coefficients of the regression models were calculated based on 17 experimental data points for each fiber and the final form of the models for polyethylene and polyester fibers are as:

For polyethylene fiber:

$P=2.84197+5.5 \times 10^{-4} L^{2}-1.79171 F_{c}^{2}-0.0138 L+4.35318 F_{c}-6.38 \times 10^{-3} L F_{c}$

For polyester fober:

$P=2.93268+3.2 \times 10^{-4} L^{2}-1.81944 F_{c}^{2}-0.02117 L+3.41776 F_{c}+0.03663 L F_{c}$

where $\mathrm{p}$ is seepage force $(\mathrm{N}), \mathrm{L}$ is fiber length $(\mathrm{mm})$ and $\mathrm{F}_{\mathrm{c}}$ is fiber content $(\%)$.

Figs.10 and 11 show the predicted values of seepage force against the measured values for the polyethylene and polyester fibers respectively. The calculated values of $\left(\mathrm{R}^{2}\right)$ and RMSE were calculated based on for the MNLR model were 0.9044 and $0.215136186 \mathrm{~N}$ for the polyethylene fiber and 0.9193 and $0.231342 \mathrm{~N}$ for the polyester fiber. It is resulted from the values of $\left(\mathrm{R}^{2}\right)$ for polyethylene and polyester fibers (0.9044 and 0.9193) that the correlation between seepage force and the influencing parameters is high. Equations 21 and 22 were used to assess the degree of significance of each parameter (fiber length and fiber content). The results show that the values of $\mathrm{DF}_{\mathrm{c}}$ (fiber content) and DL (length of fiber) are 0.086 and 0.249 for polyethylene fiber and 0.211 and 0.286 for polyester fiber. These results show that the variations of seepage force with fiber content and fiber length are positive for both fibers. It is concluded that although the variations of seepage force is more dependent on the fiber content and it is more effective for polyester than polyethylene fiber, but the fiber length and fiber content are both important parameters in variations of seepage force. The values of SL and $\mathrm{SF}_{\mathrm{c}}$ were calculated as $25.79 \%$ and $74.21 \%$ for 
the polyethylene fiber and for $42.51 \%$ and $57.49 \%$ for the polyester fiber. It is seen that both values of SL and $\mathrm{SF}_{\mathrm{c}}$ are positive for both fibers, indicating that increasing the fiber length and fiber content causes increase in the seepage force.

\section{Conclusion}

Based on the experimental data on the behavior of a randomly reinforced silty soil against piping regression models were developed for calculating the seepage velocity and seepage force. The proposed regression models were functions of percent weight of fiber, length of fiber and hydraulic gradient. The performance of the models was analyzed based on the values of $\left(\mathrm{R}^{2}\right)$ and partial derivatives showed that there is a high correlation between the experimental and calculated data. The results showed that the seepage velocity decreases with increasing the fiber length and fiber content but increases with hydraulic gradient. The variation of seepage velocity with percent of fiber and fiber length is of ascending form. 


\section{References}

[1] Sherard, J.L., Dunnigan, L.P., and Talbot, J.R. Basic properties of sand and gravel filters. J Geotech Eng 1984:110(6): 684-700.

[2] Brown, A.C., and Graham, W.J. Assessing the threat to lift from dam failure. J Am Water Resour Ass 1998: 24(6): 1303-1309.

[3] Foster, M.A., Fell, R., and Spannagle, M. The statistics of embankment dam failures and accidents. Can Geotech J 2000: 37(5): 1000-1024.

[4] Ojha, C.S.P., Singh, V.P., and Adrian, D.D. Determination of critical head in soil piping. J Hydrauli Eng 2003:129(7): 511-518.

[5] Sivakumar Babu, G.L., and Vasudevan, A.K. Seepage velocity and piping resistance of coir fiber mixed soils. J Irrig Draine Eng 2008: 134(4): 485-492.

[6] Ubilla, J., Abdoun, T., Sasaakul, L., Sharp, M., Steadman, S., Vanadat-Ellis. W., and Zimmie, T. New Orleans Levee system performance during hurricane Katrina, London Avenue and Orleans Canal South. J Geotech Geoenviron Eng 2008: 134(5): 668-680.

[7] Kumar, A., Walia, B.S., and Mohan, J. Compressive strength of fiber reinforced highly compressible clay. Constr Build Mater 2006: 20: 1063-1068.

[8] Maher, M.H., and Gray, D.H. Static response of sands reinforced with randomly distributed fibers. J Geotech Eng 1990: 116(11):1661-1677.

[9] Yetimoglu, T,, and Salbas, O. A study on shear strength of sands reinforced with randomly distributed discrete fibers. Geotext Geomembranes 2003: 21: 103110 
[10] Yetimoglu, T., Inanir, M, and Inanir, O.E. A study on bearing capacity of randomly distributed fiber reinforced sand fills overlying soft clay. Geotext Geomembranes 2005:23(2): 174-183.

[11]Park, S.S. Effect of fiber reinforcement and distribution on unconfined compressive strength of fiber-reinforced cemented sand. Geotext Geomembranes 2009: 27: 162-166.

[12] Consoli, N.C., Venrucelo, M.A., Fonini, A., Rosa, F.D. Fiber reinforced effects on sand considering a wide cementation range. Geotext Geomembranes 2009: 27(3): 196-203.

[13] Furumoto, K., Miki, H., Tsuneoka, N., and Obata, T. Model test on the piping resistance of short fiber reinforced soil and its application to river levee. In Proc. of the $7^{\text {th }}$ Int. Conf. on Geosynthetics, (P. Delmas, J.P. Goure, H.Girard Editors). Swets and Zeitlinger, Lisse: 2002, p. 1241-1244.

[14] Das, A., Jayashree, Ch., and Viswanadham, B.V.S. Effect of randomly distributed geo-fibers on the piping behaviours of embankment constructed with fly ash as a fill material. Geotext Geomembranes 2009: 27(5): 341-349.

[15] Das, A., Viswanadham, B.V.S. Experiments on the piping behaviour of geofiber-reinforced soil. Geosynth Int 2010: 17(4): 171-182.

[16] Estabragh, A.R., Soltannejad, K., and Javadi, A.A. Improving piping resistance using randomly distributed fibres. Geotext Geomembranes 2014: 42(1):15-24.

[17] Skempton, A.W., and Brogan, J.M. Experiments on piping in sandy gravels. Géotechnique 1994 : 44(3) : 449-460.

[18] Consoli, N.C., Casagrande, M.D.T., Coop, M.R. Performance of a fiberreinforced sand at large strains. Géotechnique $2007: 57(9)$ : 751-756. 
[19] Estabragh, A.R., Beytolahpour, I., andf Javadi, A.A. Effect of resin on strength of soil-cement mixture. J Mater Eng 2011:23(2): 969-976.

[20] Michalowski, R.L., and Zhao, A. Failure of fiber-reinforced granular soils. J Geotech Eng 1996: 122(3): 226-234.

[21] Michalowski, R.L., and Cermak, J. Triaxial compression of sand reinforced with fibers. J Geotech Geoenviron Eng 2003:129(2): 125-136.

[22] Ranjan, G., Vasan, R.M., and Charan, H.D. Probabilistic analysis of randomly distributed fiber-reinforced soil. J Geotech Eng 1996:122(1): 75-86. 
Tabe 1. Physical and mechanical properties of used soil

\begin{tabular}{|c|c|}
\hline Property & Value \\
\hline $\begin{array}{l}\text { Specific gravity }\left(\mathrm{G}_{\mathrm{s}}\right) \\
\text { Atterberg limits }\end{array}$ & 2.7 \\
\hline Liquid limit (\%) & 19.4 \\
\hline Plastic limit (\%) & Non plastic \\
\hline Plasticity index (\%) & - \\
\hline Particle size distribution & \\
\hline Gravel (\%) & 0 \\
\hline Sand $(\%)$ & 77 \\
\hline Silt $(\%)$ & 23 \\
\hline Clay $(\%)$ & 0 \\
\hline Effective particle size, $\mathrm{D}_{10}(\mathrm{~mm})$ & 0.05 \\
\hline Coefficient of uniformity, $\mathrm{C}_{\mathrm{u}}$ & 3.4 \\
\hline Coefficient of curvature, $C_{c}$ & 1.17 \\
\hline $\begin{array}{l}\text { USCS classification } \\
\text { Compaction characteristics }\end{array}$ & SM \\
\hline Maximum dry unit weight $\left(\mathrm{kN} / \mathrm{m}^{3}\right)$ & 18.6 \\
\hline Optimum water content (\%) & 13.2 \\
\hline
\end{tabular}


Table 2. Physical and mechanical properties of fibers

\begin{tabular}{|l|c|c|}
\hline Fiber properties & Polyethylene (No.1) & Polyester (No.2) \\
\hline Fiber type & Single fiber & Single fiber \\
Specific gravity, Gs & 0.91 & 1.24 \\
Water absorption & Nil & Nil \\
Resistance to acide & Excellent & Excellent \\
Resistance to alkaline & Excellent & Excellent \\
Diameter (mm) & 0.28 & 0.20 \\
Tensile strength (MPa) & 400 & 500 \\
Modulus of elasticity & 2350 & 2500 \\
(MPa) & & \\
\hline
\end{tabular}


Table 3.Summery of piping test results for fiber polyethylene No.1

\begin{tabular}{|c|c|c|c|c|c|}
\hline $\begin{array}{c}\text { Length } \\
(\mathrm{mm})\end{array}$ & $\begin{array}{c}\text { Fiber } \\
\text { inclusion } \\
(\%)\end{array}$ & $\begin{array}{c}\mathrm{W}_{\mathrm{opt}} \\
(\%)\end{array}$ & $\begin{array}{c}\gamma_{\mathrm{dmax}} \\
\left(\mathrm{kN} / \mathrm{m}^{3}\right.\end{array}$ & $\mathrm{i}_{\text {cr }}$ & $P(\mathrm{~N})$ \\
\hline \multirow{4}{*}{5} & - & 13.2 & 18.6 & 1.55 & 3.04 \\
\hline & 0.5 & 12.4 & 18.0 & 2.15 & 4.22 \\
\cline { 2 - 6 } & 0.75 & 12.0 & 17.7 & 2.35 & 4.61 \\
\cline { 2 - 6 } & 1.0 & 11.6 & 17.6 & 2.35 & 4.61 \\
\cline { 2 - 6 } & 1.25 & 11.0 & 17.0 & 2.35 & 4.61 \\
\hline \multirow{5}{*}{25} & 0.5 & 12.5 & 18.0 & 2.15 & 4.22 \\
\cline { 2 - 6 } & 0.75 & 11.8 & 17.8 & 2.55 & 4.61 \\
\cline { 2 - 6 } & 1.0 & 11.4 & 17.7 & 2.55 & 5.0 \\
\hline \multirow{5}{*}{35} & 1.25 & 11.0 & 17.7 & 2.55 & 5.0 \\
\cline { 2 - 6 } & 0.5 & 12.7 & 17.8 & 2.15 & 4.22 \\
\cline { 2 - 6 } & 0.75 & 12.3 & 17.7 & 2.75 & 5.4 \\
\cline { 2 - 6 } & 1.0 & 12.2 & 17.6 & 2.95 & 5.8 \\
\hline \multirow{5}{*}{50} & 1.25 & 11.8 & 17.5 & 3.15 & 6.2 \\
\cline { 2 - 6 } & 0.5 & 13.0 & 17.8 & 2.55 & 4.91 \\
\cline { 2 - 6 } & 0.75 & 12.4 & 17.6 & 2.75 & 5.4 \\
\cline { 2 - 6 } & 1.0 & 12.2 & 17.5 & 3.15 & 6.18 \\
\hline
\end{tabular}

Table 4. Summery of piping test results for fiber polyester No.2

\begin{tabular}{|c|c|c|c|c|c|}
\hline $\begin{array}{l}\text { Length } \\
(\mathrm{mm})\end{array}$ & $\begin{array}{c}\text { Fiber } \\
\text { inclusion } \\
(\%)\end{array}$ & $\begin{array}{l}W_{\text {opt }} \\
(\%)\end{array}$ & $\begin{array}{c}\gamma_{\mathrm{dmax}} \\
\left(\mathrm{kN} / \mathrm{m}^{3}\right.\end{array}$ & $\mathrm{i}_{\mathrm{cr}}$ & $P(\mathrm{~N})$ \\
\hline- & - & 13.2 & 18.6 & 1.55 & 3.04 \\
\hline \multirow{4}{*}{5} & 0.5 & 12.8 & 18.1 & 2.15 & 4.22 \\
\hline & 0.75 & 12.6 & 17.6 & 2.75 & 5.4 \\
\hline & 1.0 & 12.1 & 17.5 & 2.75 & 5.4 \\
\hline & 1.25 & 11.9 & 17.4 & 2.75 & 5.4 \\
\hline \multirow{4}{*}{25} & 0.5 & 12.8 & 17.7 & 2.35 & 4.61 \\
\hline & 0.75 & 12.4 & 17.5 & 2.35 & 4.61 \\
\hline & 1.0 & 12.0 & 17.4 & 2.75 & 5.4 \\
\hline & 1.25 & 11.6 & 17.2 & 2.75 & 5.4 \\
\hline \multirow{4}{*}{35} & 0.5 & 12.65 & 17.9 & 2.35 & 3.04 \\
\hline & 0.75 & 12.5 & 17.6 & 2.75 & 5.4 \\
\hline & 1.0 & 12.15 & 17.2 & 2.75 & 5.4 \\
\hline & 1.25 & 11.8 & 17.0 & 2.75 & 5.4 \\
\hline \multirow{4}{*}{50} & 0.5 & 12.8 & 17.1 & 2.55 & 5.0 \\
\hline & 0.75 & 12.5 & 16.4 & 2.75 & 5.4 \\
\hline & 1.0 & 12.36 & 15.6 & 3.15 & 6.2 \\
\hline & 1.25 & 12.24 & 15.11. & 3.15 & 6.2 \\
\hline
\end{tabular}


Table 5. Values of $\mathrm{R}^{2}$ and RMSE for different fibers and models

\begin{tabular}{|c|c|c|c|}
\hline Fiber & Model & $\mathrm{R}^{2}$ & RMSE $(\mathrm{cm} / \mathrm{s})$ \\
\hline Polyethylene & MNLR $^{\mathrm{a}}$ & 0.9595 & 0.000176944 \\
\hline Polyester & MNLR $^{\mathrm{a}}$ & 0.985 & 0.0000928432 \\
\hline Polyethylene & MLR $^{\mathrm{b}}$ & 0.935 & 0.000224165 \\
\hline Polyester & MLR & 0.9663 & 0.000139276 \\
\hline
\end{tabular}

a- Multipel Non- Linear Regression

b- Multiple Linear Regression

Table 6. Significant different parameters in predicting the seepage velocity

\begin{tabular}{|c|c|c|c|c|c|}
\hline \multicolumn{3}{|c|}{ Polyethylene } & \multicolumn{3}{c|}{ Polyester } \\
\hline $\mathrm{DF}_{\mathrm{e}}$ & $\mathrm{D}_{\mathrm{i}}$ & $\mathrm{DL}$ & $\mathrm{DF}_{\mathrm{e}}$ & $\mathrm{D}_{\mathrm{i}}$ & $\mathrm{DL}$ \\
\hline-0.13 & 1.08 & -0.178 & -0.2 & 1.37 & -0.08 \\
\hline $\mathrm{SF}_{\mathrm{e}}(\%)$ & $\mathrm{Si}(\%)$ & $\mathrm{SL}(\%)$ & $\mathrm{SF}_{\mathrm{e}}(\%)$ & $\mathrm{Si}(\%)$ & $\mathrm{SL}(\%)$ \\
\hline 9.71 & 78.1 & 12.19 & 16.04 & 72.25 & 6.2 \\
\hline
\end{tabular}




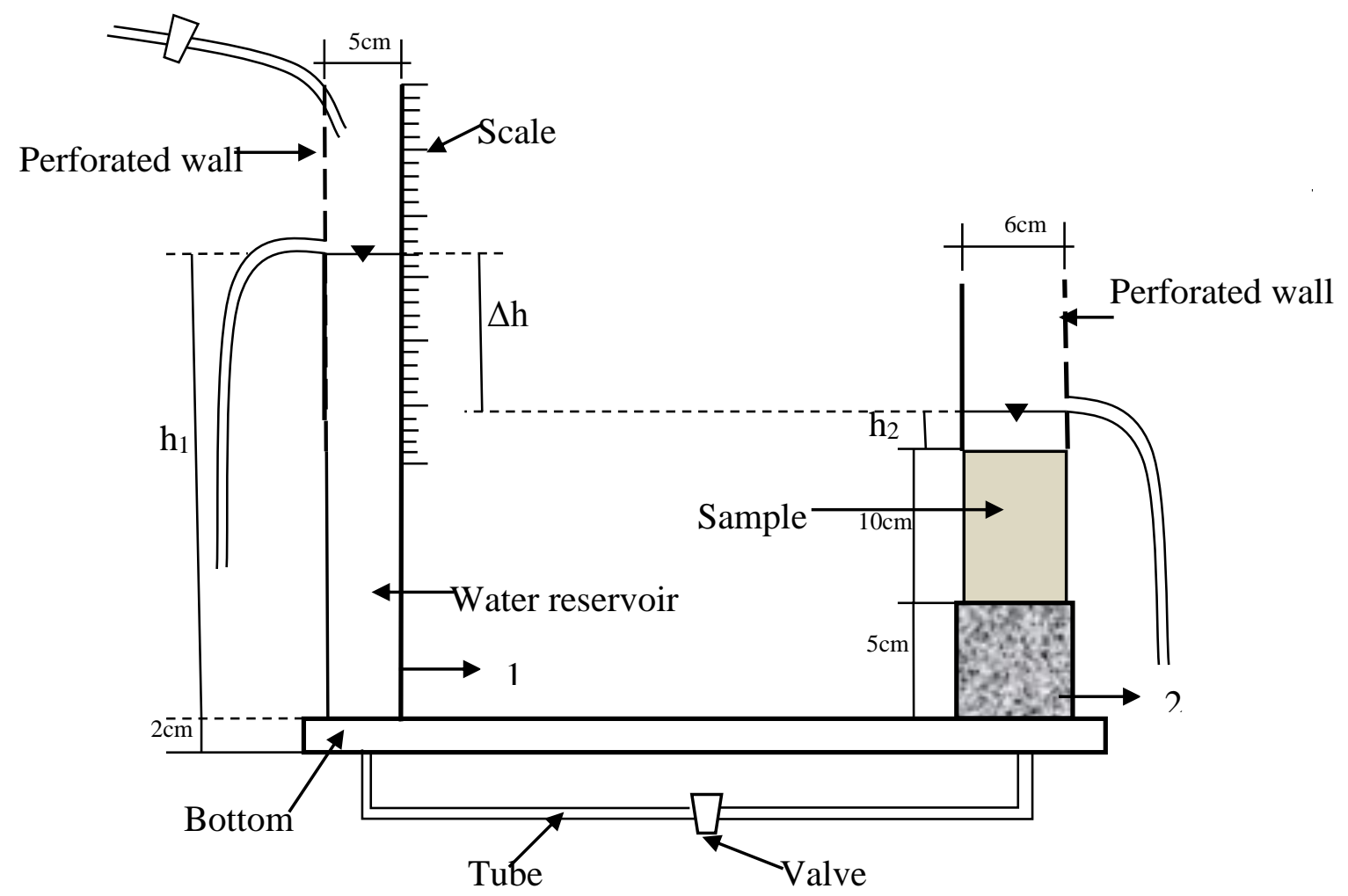

Fig.1 Apparatus 


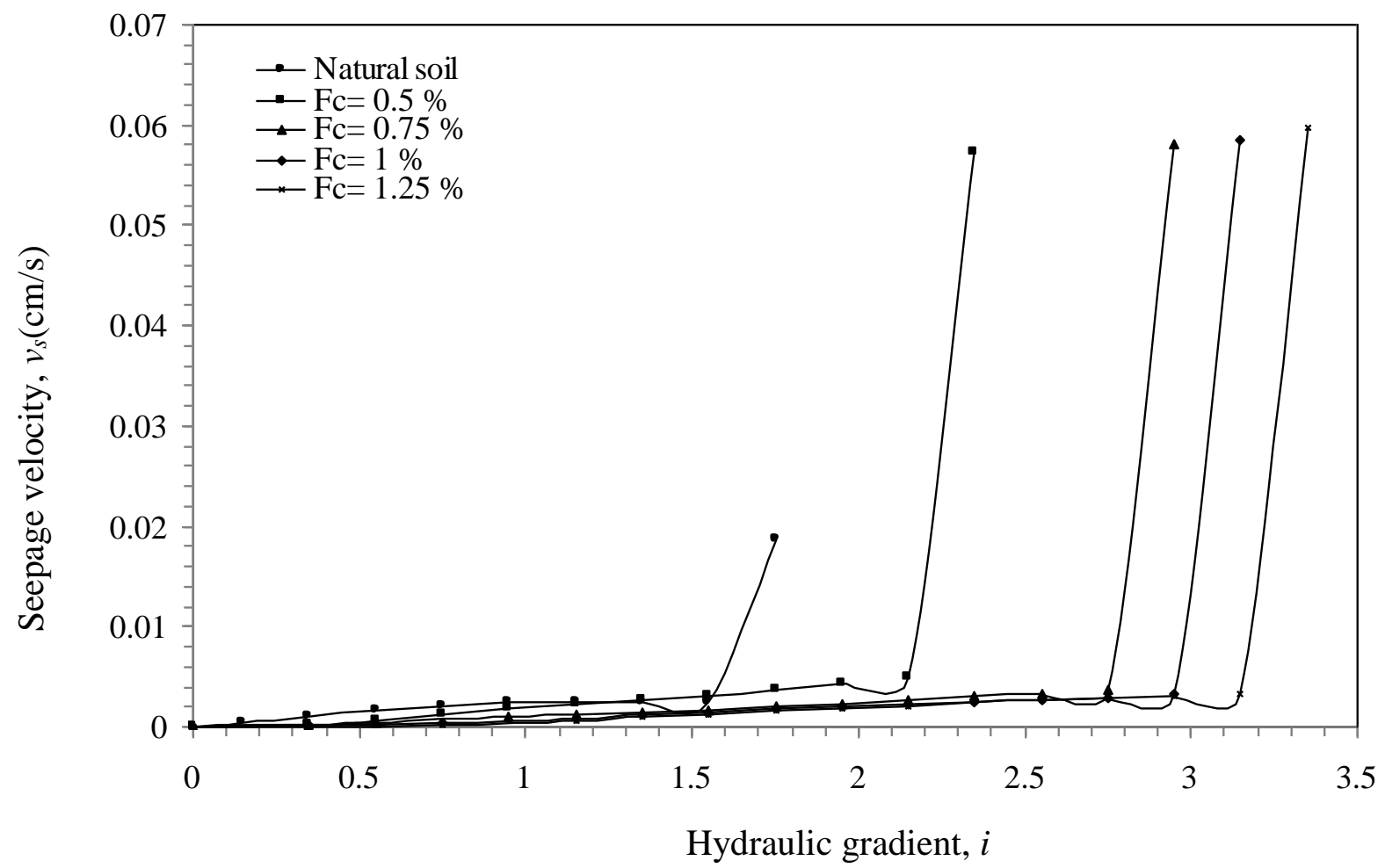

Fig.2. Variations of seepage velocity against hydraulic gradient for polyethylene fiber with $35 \mathrm{~mm}$ length at different fiber contents 


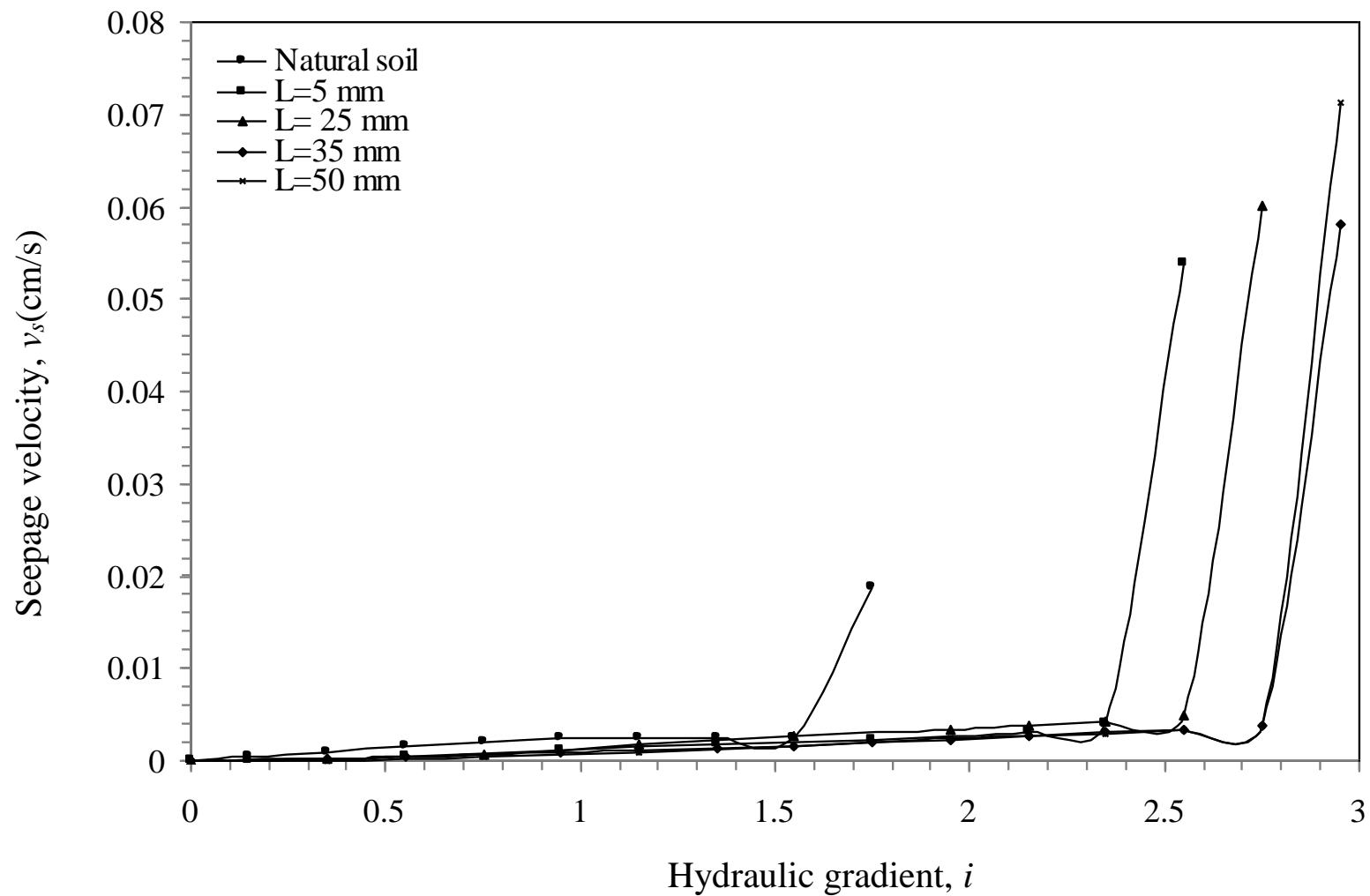

Fig.3. Variations of seepage velocity against hydraulic gradient for different lengths of polyethylene fiber at $0.75 \%$ fiber content 


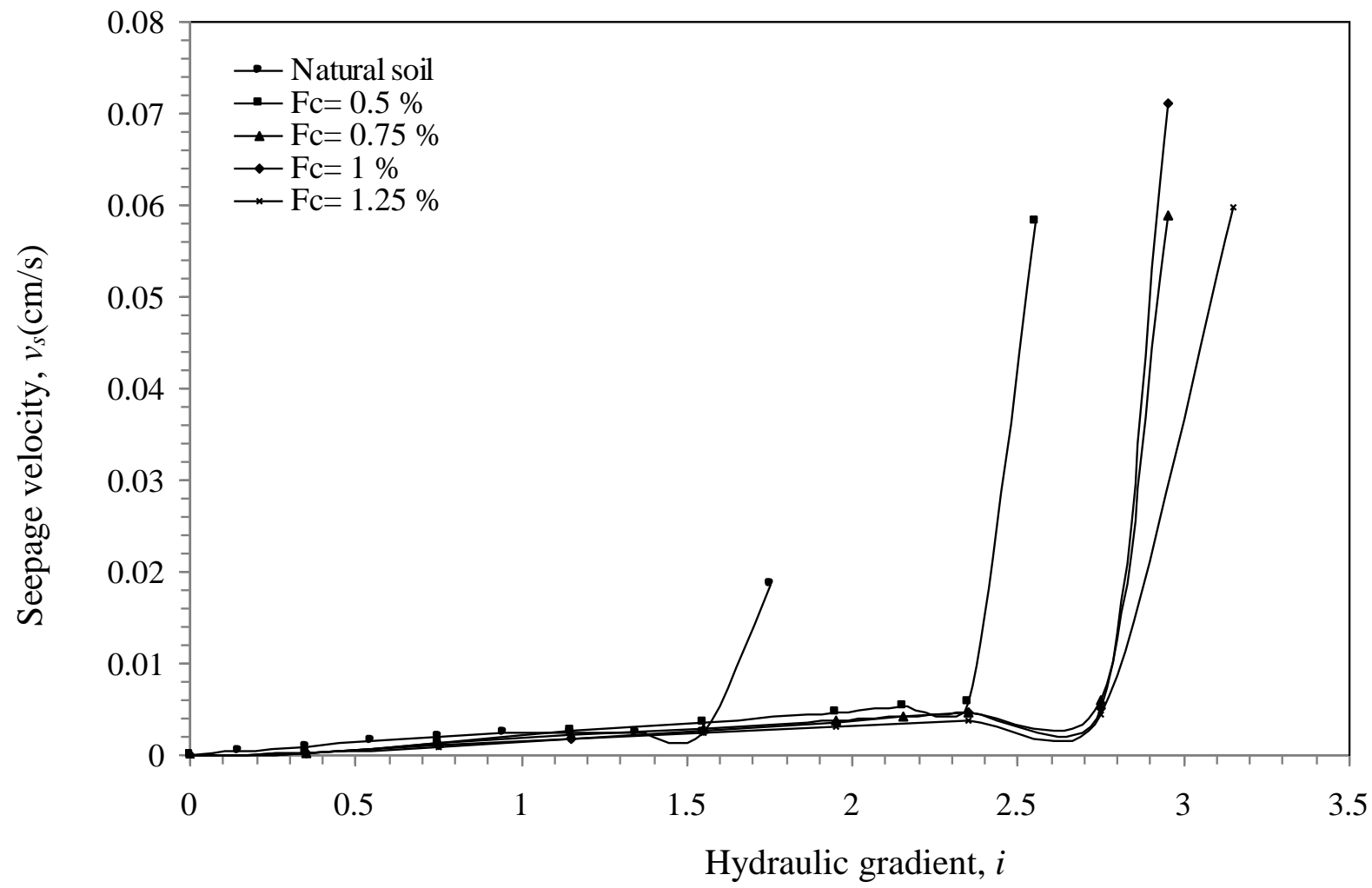

Fig.4. Variations of seepage velocity against hydraulic gradient for polyester fiber at length of $35 \mathrm{~mm}$ and different fiber contents 


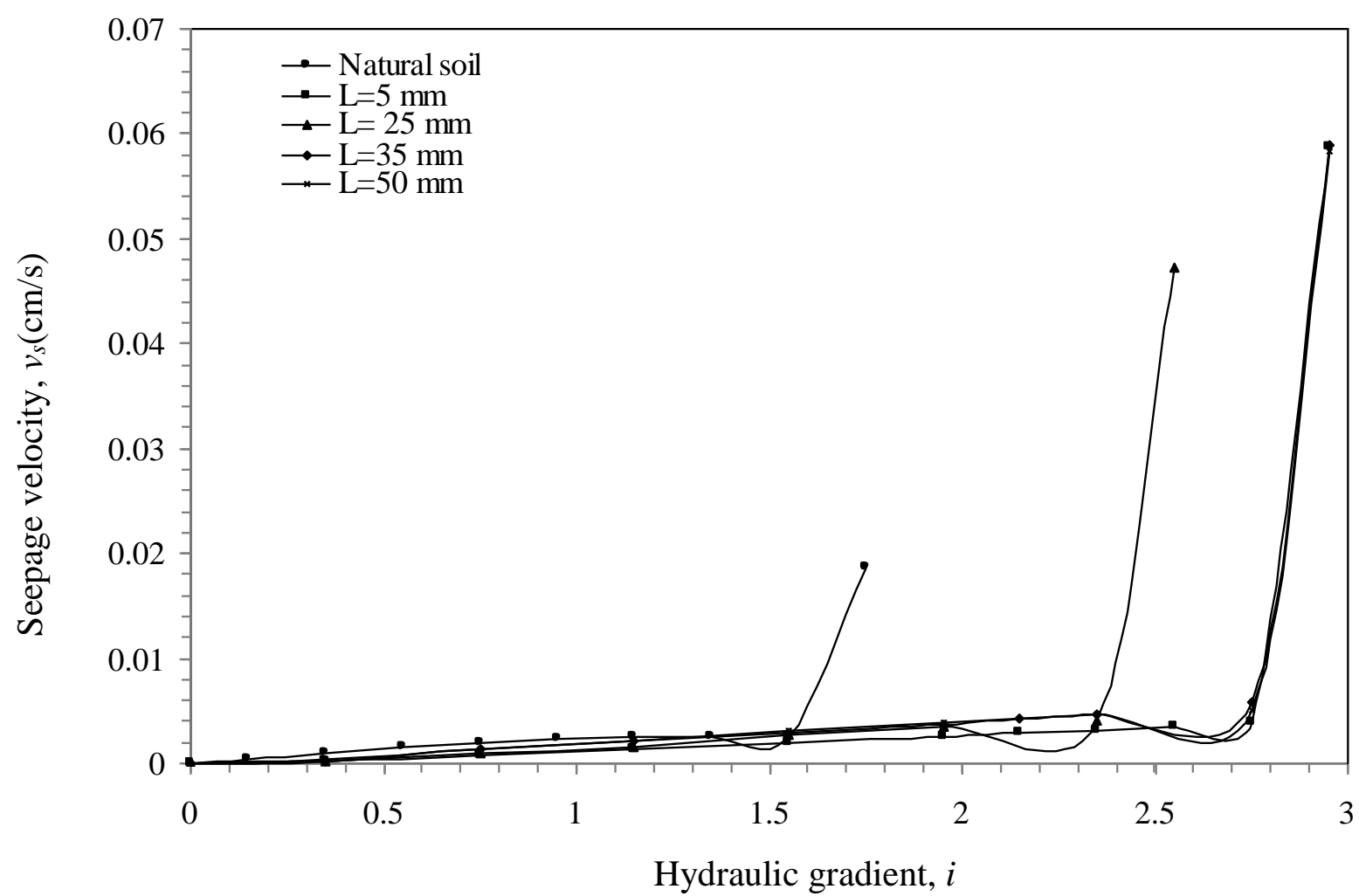

Fig.5. Variations of seepage velocity against hydraulic gradient for polyester fiber with different lengths at 0.75 percent fiber content 


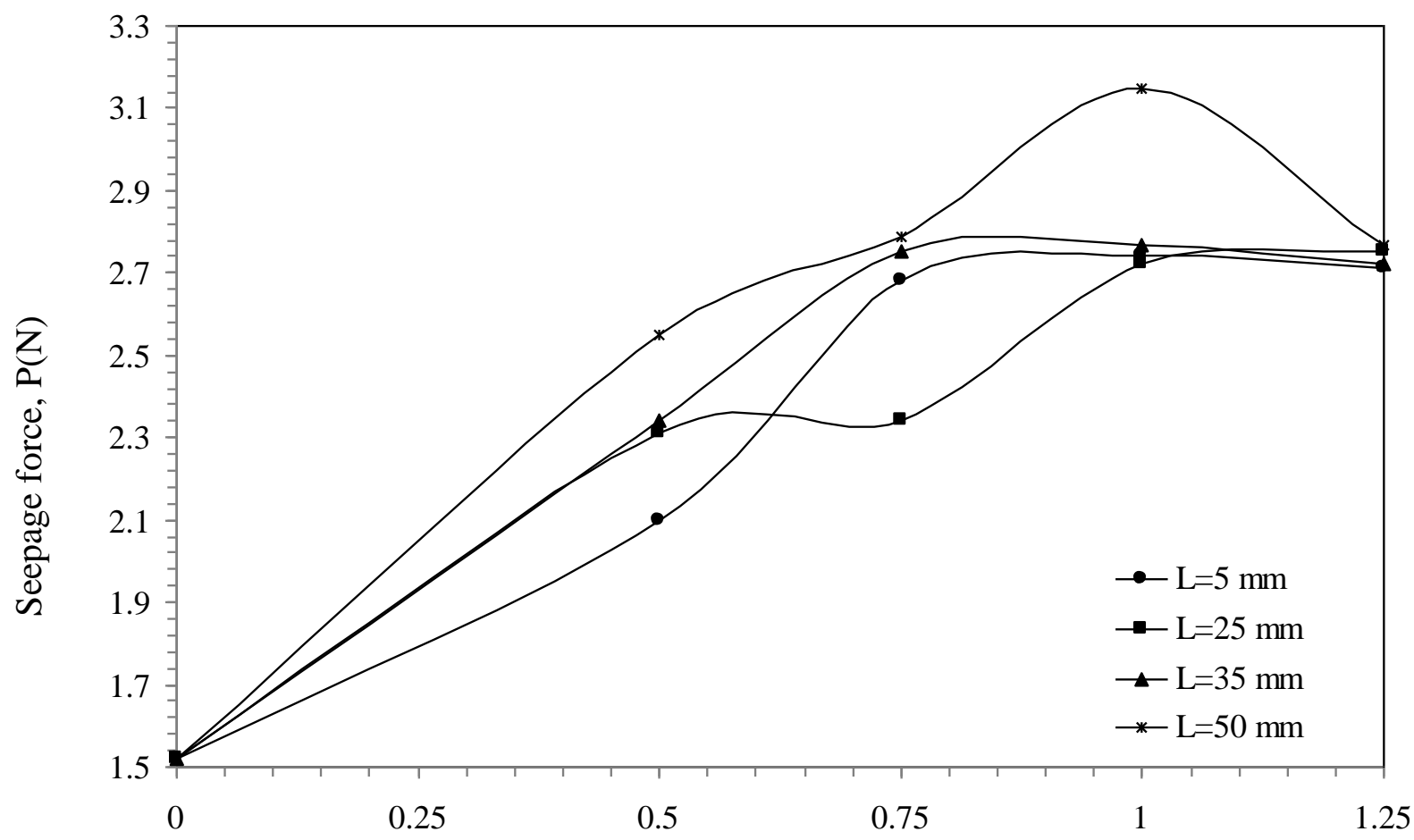

Fiber content (\%)

Fig.6. Variations of seepage force against percent of polyethylene fiber or different fiber lengths 


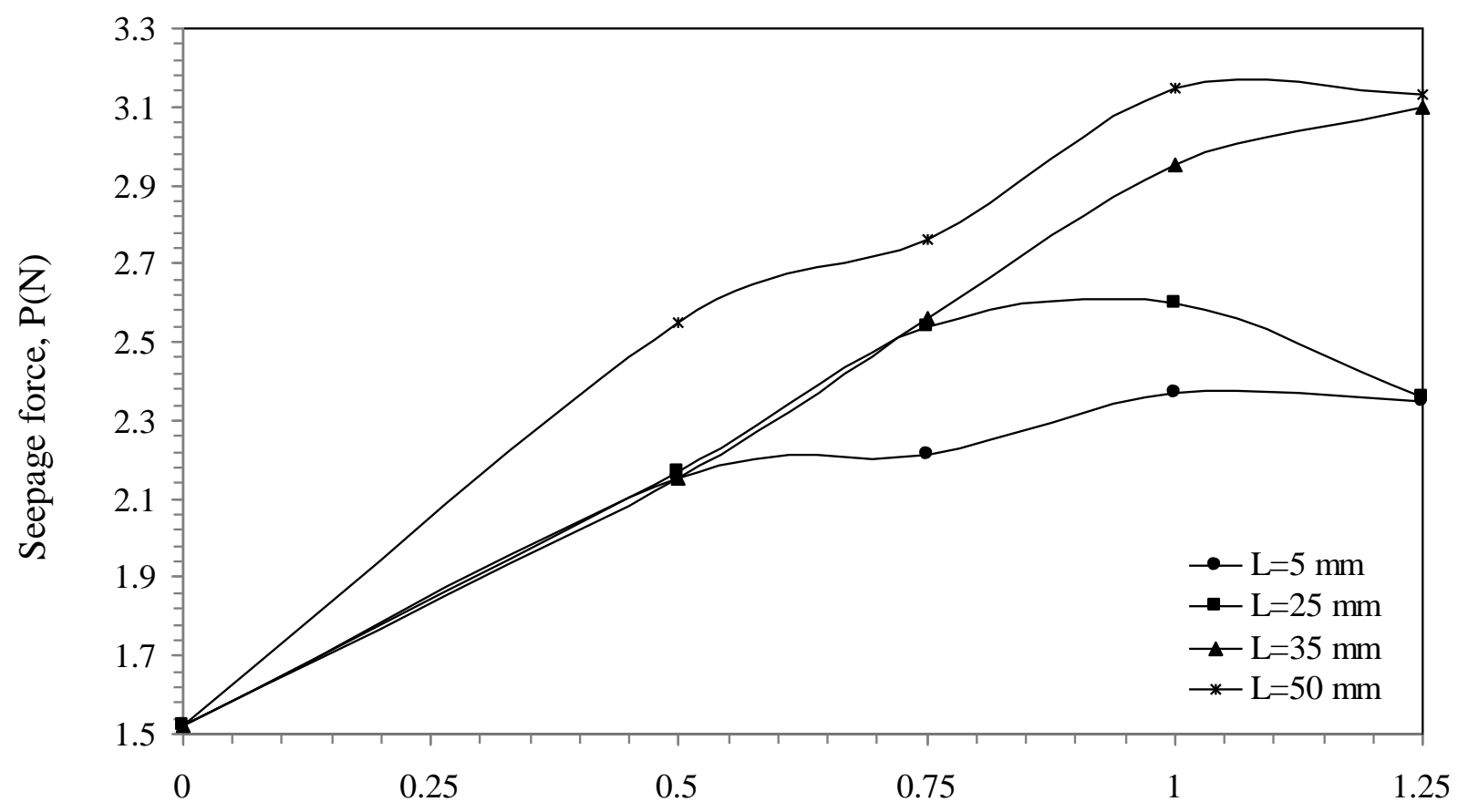

Fiber content $(\%)$

Fig.7. Variations of seepage force against fiber content for polyester fiber for different lengths of fiber 


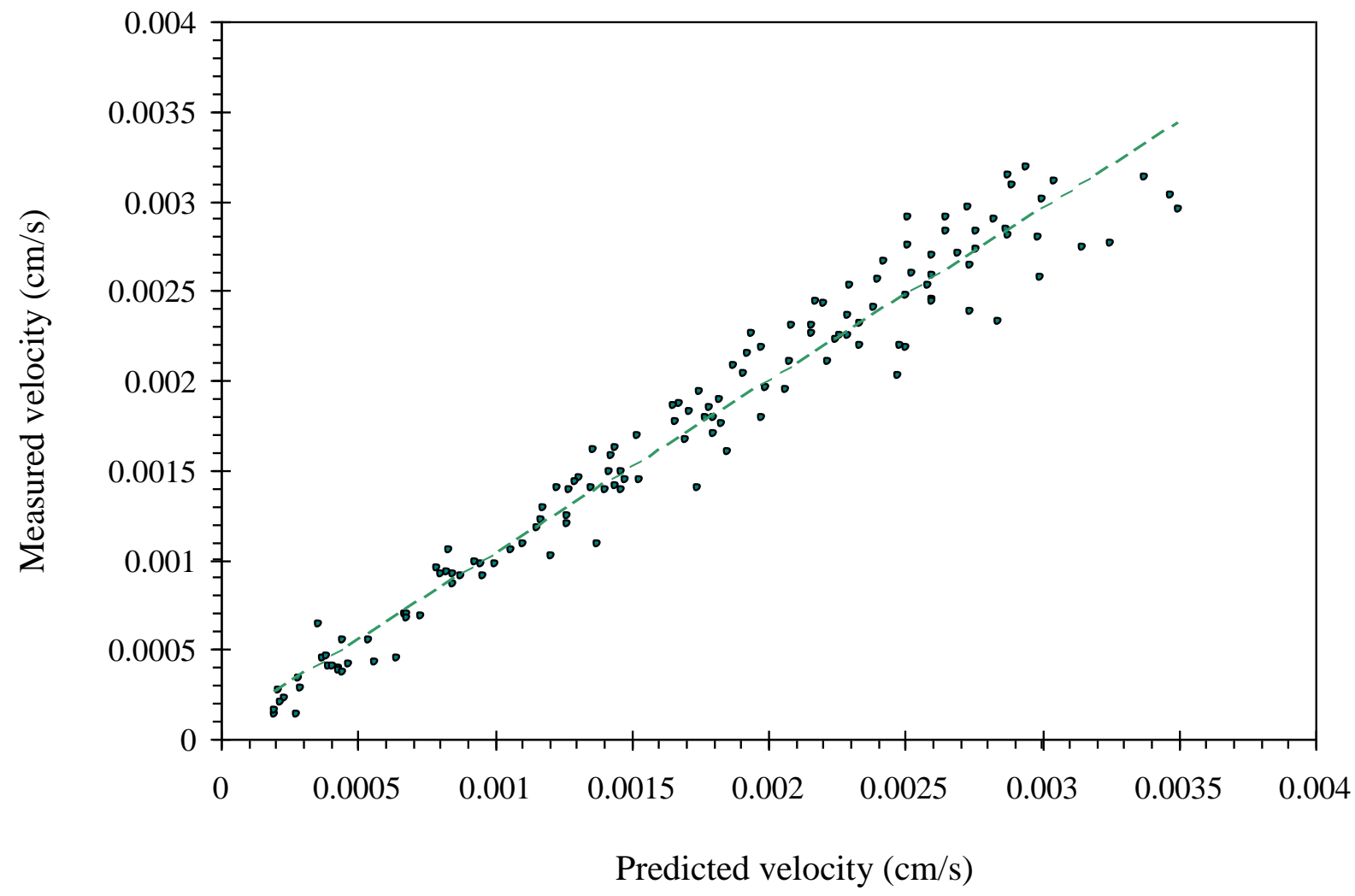

Fig.8. Variations of measured velocity against predicted velocity for polyethylene fiber 


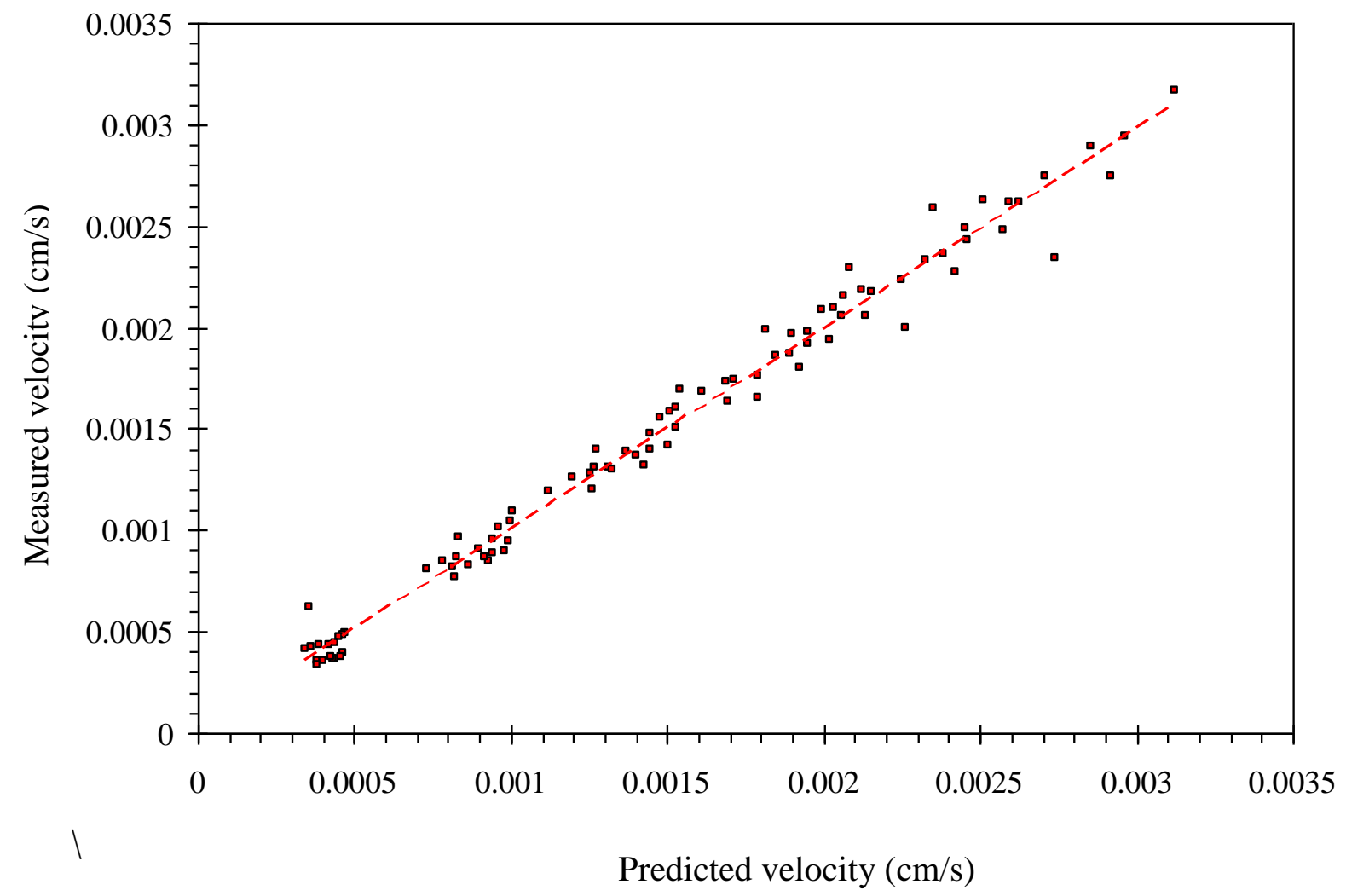

Fig.9. Variations of measured velocity against predicted velocity for polyester fiber 


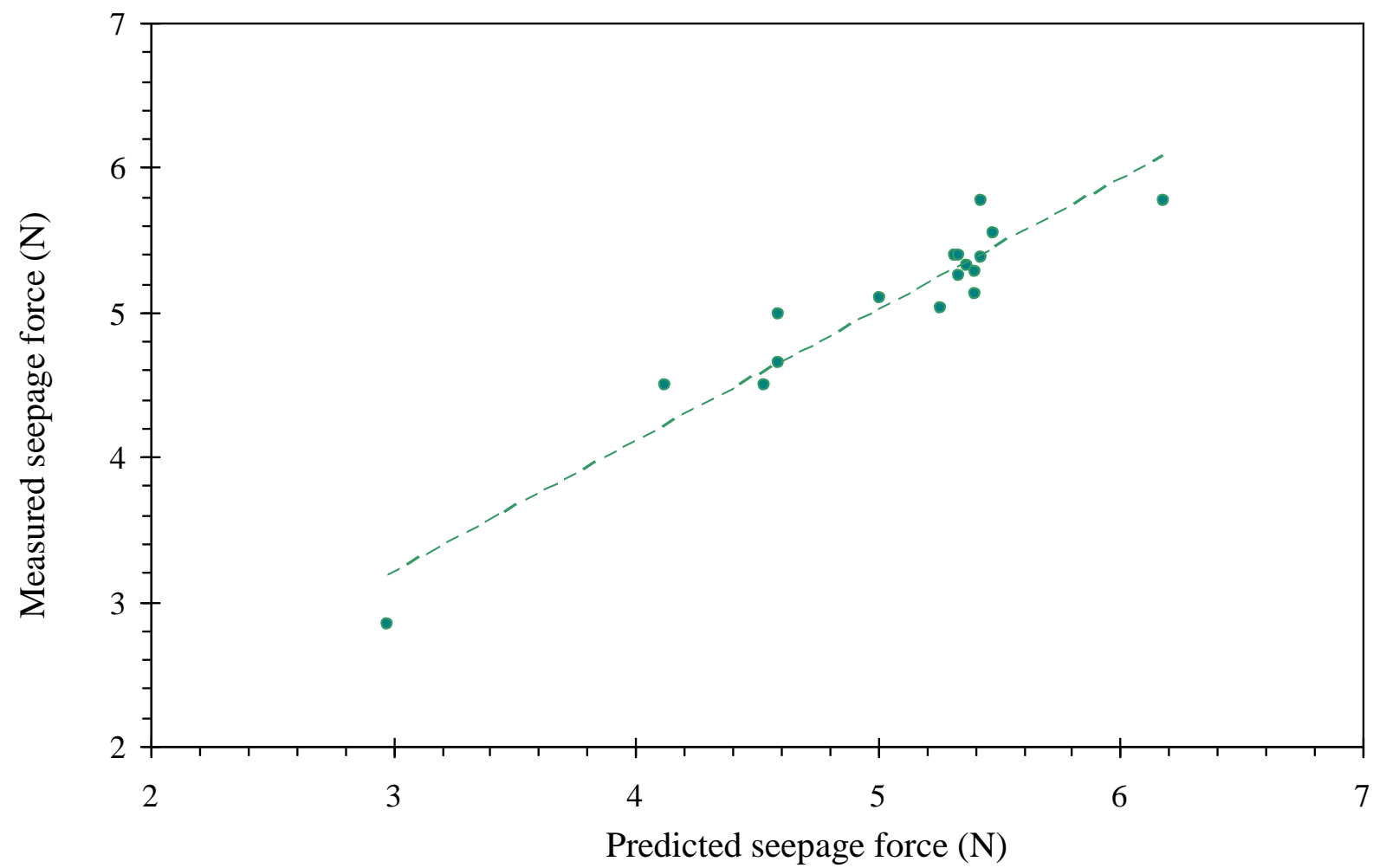

Fig.10. Variation of measured against predicted seepage force for polyethylene fiber 


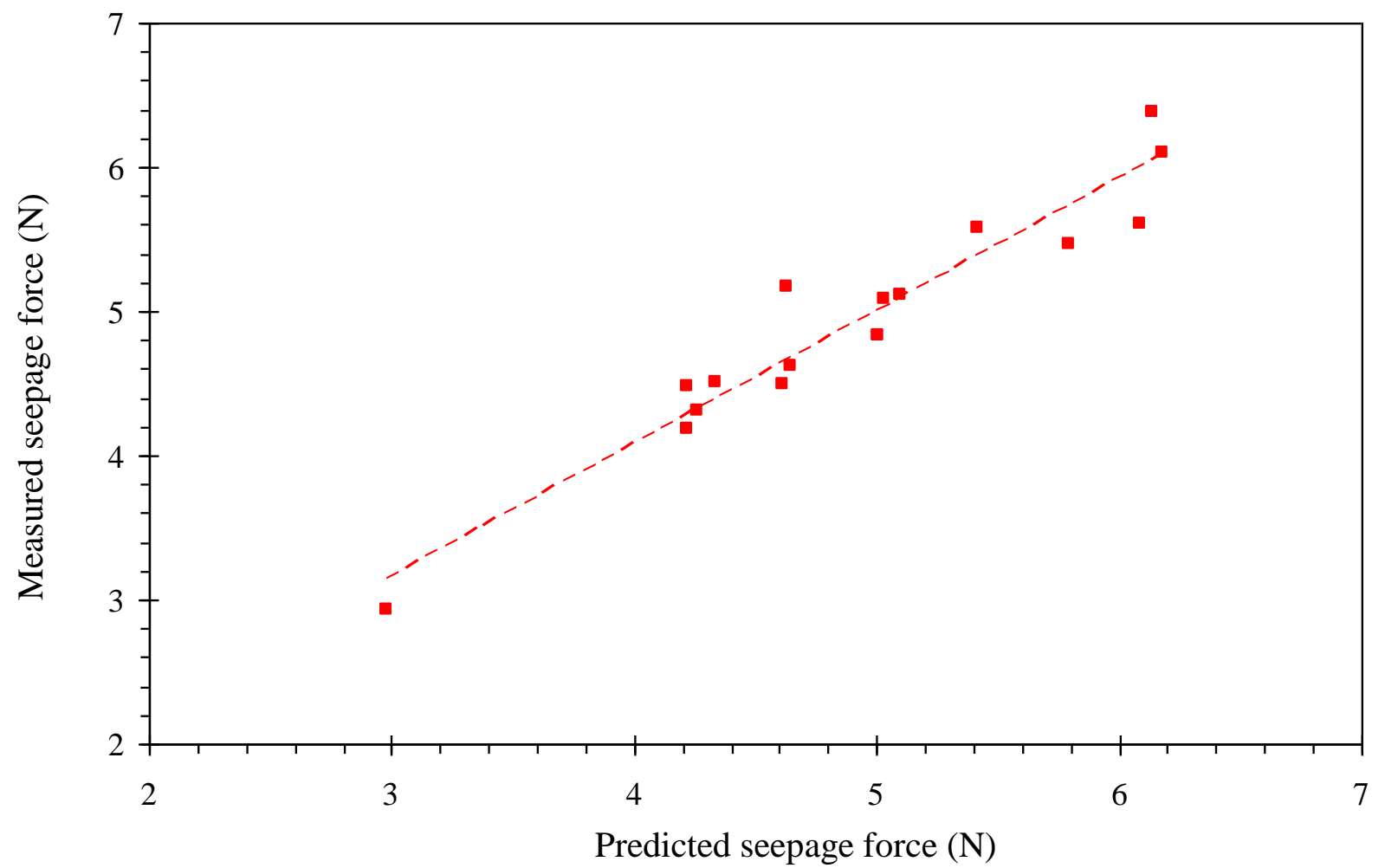

Fig.11. Variation of measure against predicted seepage force for polyester fiber 